\title{
Microscopic properties of MPCVD diamond coatings studied by micro-Raman and micro-photoluminescence spectroscopy
}

\author{
KALYAN S PAL ${ }^{1,3}$, AWADESH K MALLIK ${ }^{1}$, NANDADULAL DANDAPAT ${ }^{1}$, NIHAR R RAY ${ }^{2}$, \\ SOMESWAR DATTA ${ }^{1}$, SANDIP BYSAKH ${ }^{1, *}$ and BICHITRA K GUHA ${ }^{3}$ \\ ${ }^{1}$ CSIR - Central Glass \& Ceramics Research Institute, Kolkata 700 032, India \\ ${ }^{2}$ Centre for Nano Science and Surface Physics, Surface Physics Division, Saha Institute of Nuclear Physics, \\ 1/AF, Bidhannagar, Kolkata 700 064, India \\ ${ }^{3}$ Department of Physics, Indian Institute Engineering Science \& Technology, Howrah 711 103, India
}

MS received 17 June 2014; revised 29 September 2014

\begin{abstract}
Diamond coatings were deposited on silicon (100) substrate using the microwave plasma chemical vapour deposition (MPCVD) technique at different process conditions. Process parameters such as $\mathrm{CH}_{4}-\mathrm{H}_{2}$ gas mixture concentration, microwave power, chamber pressure and substrate temperature were varied. The diamond coatings were characterized by micro-Raman and micro-photoluminescence (PL) spectroscopy techniques. In this paper we report a comparison of the overall quality of MPCVD polycrystalline diamond coatings grown under different processing conditions in terms of stress distribution, thickness uniformity and surface roughness. Micro-Raman spectroscopy studies over various points on the deposited coating showed that the Raman line widths of diamond peak varied from 3.2 to $18.3 \mathrm{~cm}^{-1}$ with the variation of $\mathrm{CH}_{4}$ and $\mathrm{H}_{2}$ gas concentration. The micro-PL spectra suggested the presence of impurity concentration and defects within the diamond coating synthesized at different processing conditions. Transmission electron microscopy (TEM) images provide the direct evidence of the presence of crystal defects which corroborates the Raman and PL results. The coherence scanning interferometry (CSI) showed that surface roughness of diamond coating varied from 0.43 to $11 \mu \mathrm{m}$ with thickness at different positions of the three coating samples. It has been concluded that Raman line-width broadening and Raman-shift are due to the presence of crystal defects as well as non-uniform distribution of stresses present in the diamond crystals of the coating, due to the incorporation of $\mathrm{Si}$ as impurity element and non-uniform temperature distribution during growth. Defect density gets reduced at higher processing temperatures. It is also being proposed that better thickness uniformity and lower surface roughness can be achieved for coatings deposited at low methane concentration under optimized process conditions.
\end{abstract}

Keywords. Raman spectroscopy; photoluminescence; diamond; transmission electron microscopy.

\section{Introduction}

Over the last fifty years the world scientific community has become interested in growing synthetic diamond by chemical vapour deposition (CVD) processes at low pressures due to unique combination of exceptional physical properties of natural diamond. ${ }^{1}$ The present challenge is to produce low cost, high quality and high performance materials with a great variety of potential applications in micromechanics, microelectronics, optics, and, more generally, in all those fields where advanced devices are required to operate in extreme conditions. Nowadays, polycrystalline diamond films can be produced in a controlled way by microwave plasma enhanced chemical vapour deposition (MPCVD) technique to obtain excellent physical properties exhibited by natural diamond. ${ }^{2,3}$ However, compared to natural diamond, polycrystalline CVD diamond films grown on non-diamond substrates generally contain a relatively high

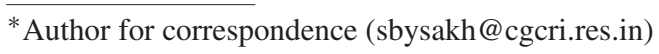

concentration of impurities, crystalline defects within grains and non-diamond inclusions at grain boundaries. The presence of defects and non-diamond inclusions significantly affect the desired properties of diamond coating. ${ }^{4}$ In recent times, the applications of diamond films and coatings are limited primarily due to their high cost and difficulty in obtaining good quality. The macroscopic properties such as thermal conductivity, heat capacity, electrical conductivity or optical clarity directly depend on film quality ${ }^{5}$ and are determined by microscopic properties of the films. In this respect, the main technical challenge is to improve the intrinsic quality of diamond films by reducing the density of crystal defects and impurities incorporated during the growth process. Therefore, a key role is played by characterization studies, which clarify the correlation between the growth conditions and microscopic structural properties of the diamond films and thereby, help in optimization of the growth process.

Raman spectroscopy is a powerful nondestructive tool for evaluating the quality of diamond as well as impurities present in diamond samples. ${ }^{6,7}$ Generally, Raman 
spectroscopy represents a very well-known diagnostic technique for identification of the different carbon allotropes (e.g., diamond, graphite and buckyballs) present in the sample. ${ }^{8}$ Raman scattering from carbon is always a resonant process, in which the carbon-carbon bonds having $s p, s p^{2}$ and $s p^{3}$ configurations have band gaps between 0 and $5.5 \mathrm{eV}$ and match the excitation energy of IR-vis-UV Raman spectrometers. ${ }^{9}$ The characteristic Raman spectrum for natural diamond exhibits a single sharp line at $1332 \mathrm{~cm}^{-1}$, having full-width at half-maximum (FWHM) of about $2 \mathrm{~cm}^{-1}$, while natural single-crystal graphite shows a single Raman peak at $1580 \mathrm{~cm}^{-1}$. There may be an additional band at about $1350 \mathrm{~cm}^{-1}$, activated by structural disorder that is present in polycrystalline graphite. Amorphous carbon exhibits a broad asymmetric band, centred around $1500 \mathrm{~cm}^{-1}$ and comprising of two or more overlapping components located between two graphite bands. ${ }^{6,7}$

On the other hand, photoluminescence (PL) spectroscopy is commonly used for studying the nature and the distribution of crystal defects and impurity-induced optical centres in diamond films. Many researchers have studied the widths and the line shapes of zero phonon lines (ZPLs) of photoluminescent defects of $\mathrm{H} 3$ at $575 \mathrm{~nm}$ and $1.945 \mathrm{eV}$, which can be related to the state of internal stress and the nature of the dominant defects. ${ }^{10-12}$

Donato and co-workers ${ }^{6,7}$ carefully performed Raman spectroscopy of diamond films grown on Si substrates by microwave plasma CVD under different methane concentrations and substrate temperatures in order to assess the influence of the growth conditions on the crystalline film quality, as measured from the line width of the diamond peak. Micro-PL measurements performed on the growth surface and on the cross-section of the samples had shown higher amount of Si impurities in films having lower PL yield. These results are in good agreement with the stress values from the Raman measurements and it can also be compared with the growth history of the sample. ${ }^{13}$ Micro-Raman spectroscopy measurement is necessary to understand the stress distribution, which has good sensitivity to the analysis of impurities and defects associated with non-diamond phases. ${ }^{14}$

Recent progress in laser Raman spectroscopy allows micro-Raman studies at the micrometre scale in different laser excitation wavelengths from UV to infrared. ${ }^{15,16}$ In particular, the characteristic sharp line of diamond is generally shifted with respect to $1332 \mathrm{~cm}^{-1}$ due to internal stress, and it is much broader than that in natural diamond due to crystalline defects or an inhomogeneous distribution of stress. The shifts of the characteristic diamond line showed an apparent dependence on the thickness of the film. In case of thin films the Raman line shifts to wave numbers higher than $1332 \mathrm{~cm}^{-1}$, correspond to compressive stresses, while for relatively thicker films the shifts are towards lower wave numbers and this means a tensile stress. The change in the nature of the total residual stress from compressive to tensile indicates a possible variation in the nature and relative magnitudes of intrinsic and thermal stresses. ${ }^{17}$ For example, in the case of high-quality polycrystalline diamond films,
2D stress or defect images were deduced from the Raman spectra. Furthermore, in the case of thick diamond films, the internal stress is relieved by crack formation and in some cases, high local stresses (both compressive and tensile) were also observed within diamond grains. In particular, defects were found close to the grain boundaries of the deposited film. ${ }^{18}$ Several groups investigated the evolution of stress in diamond layers on the basis of both experimental and theoretical considerations in order to develop a comprehensive overview of the generation of residual stresses. The large local compressive stresses associated with grain coalescence and the tensile stresses due to temperature gradient and surface energy effects can be measured using micro-Raman spectroscopy. ${ }^{17,19}$ Therefore, such spectroscopy studies can provide better understanding of the influence of growth conditions on the microscopic structure and properties of the diamond coatings.

In the present work, a systematic micro-Raman spectroscopy analysis has been carried out on the as-grown surface of the diamond coating over a large surface area. The Raman line width of the diamond peak was used as a measure to evaluate the crystalline quality. The intrinsic stress distribution throughout the large area diamond coating was also obtained. Micro-PL spectroscopy was used to investigate the defect formation and impurity present in the diamond coating. The three-dimensional surface topography was studied using non-contact optical mode coherence scanning interferometry (CSI) for the measurement of the average surface roughness of the diamond coating at different points. Although correlative Raman line spectrum and PL studies have previously been reported on CVD diamond sample, no literature on systematic micro-Raman and micro-PL spectroscopy as well as sub-micrometre resolution CSI study is available on CVD diamond coating. In our study, these correlative techniques were used to analyse the microscopic properties like crystalline quality in terms of different stress components, defect concentration and surface topography of diamond coatings and their dependence on various process parameters. Thus, the present study opens up a new way to explore the unique microscopic properties of diamond coatings deposited on Si substrates for optimization of the growth parameters.

\section{Theory}

In Raman spectroscopy, a laser beam of particular frequency illuminates the sample material. The photons from the laser beam interact with the lattice phonons and get scattered inelastically. As a result the photons suffer a frequency shift by a value which is characteristic of the sample material. Thus, frequency and line width of the Raman peak convey the information about the nature and structure of the diamond material. For example, diamond has a first-order characteristics Raman line at $1332 \mathrm{~cm}^{-1} .8$

In a perfect crystal, the sample should be stress free so that the Raman peak appears at its theoretical position. When 
the crystal is subjected to stresses by external forces or, due to internal defects the frequency of the lattice phonons is slightly affected and thus there occurs a shift in the frequency of the Raman peak. In this way, one can determine the stresses present in the sample by careful measurements of the shift of charcteristic Raman peak relative to its unstressed frequency. Generation of compressive stress and tensile stress are denoted by the shift of the peak to higher frequencies and lower frequencies, respectively. The amount of shift can be converted to a stress quantity using the equation as follows: ${ }^{11,12}$

$$
v_{\mathrm{o}}-v_{\mathrm{m}}=\alpha \sigma
$$

where $v_{\mathrm{o}}$ is the position of the stress-free Raman line, $v_{\mathrm{m}}$ the measured frequency of the Raman line, $\sigma$ the stress present (in $\mathrm{GPa}$ ) and $\alpha$ the coefficient of stress-induced frequency shift.

Many authors have determined the average value of $\alpha$ as $2.88 \pm 0.17 \mathrm{~cm}^{-1} / \mathrm{GPa}$ in diamond under hydrostatic uni-axial conditions where there is no splitting in the characteristic spectra. ${ }^{11,12}$ So uni-axial stress can be evaluated using the following relationship:

$$
\sigma_{\mathrm{u}}=-0.347\left(v_{\mathrm{u}}-v_{\mathrm{o}}\right)(\mathrm{GPa}),
$$

where $v_{\mathrm{o}}$ is the position of the stress-free Raman line, $v_{\mathrm{u}}$ the observed position of the Raman line under uni-axial conditions.

Nibennanoune et $a l^{20}$ investigated the biaxial residual stress by employing Raman-shift as well as splitting of a Raman peak into singlet and doublet using the following relations:

$$
\begin{aligned}
& \sigma_{\mathrm{s}}=-1.08\left(v_{\mathrm{s}}-v_{\mathrm{o}}\right)(\mathrm{GPa}) \text { for singlet phonons, } \\
& \sigma_{\mathrm{d}}=-0.384\left(v_{\mathrm{d}}-v_{\mathrm{o}}\right)(\mathrm{GPa}) \text { for double phonons, }
\end{aligned}
$$

where $v_{\mathrm{o}}$ corresponds to the stress-free diamond peak with $v_{\mathrm{o}}=1332 \mathrm{~cm}^{-1}, v_{\mathrm{s}}$ the observed maximum of the singlet and $v_{\mathrm{d}}$ the maximum of the doublet in the spectrum. If splitting of the Raman line is not obvious, the observed peak position $\nu_{\mathrm{c}}$ is assumed to be located at the centre between the singlet $v_{\mathrm{s}}$ and doublet $v_{\mathrm{d}}$ using $v_{\mathrm{c}}=1 / 2\left(v_{\mathrm{s}}+v_{\mathrm{d}}\right)$. Thus, from equations (3) and (4) we obtain

$$
\sigma_{\mathrm{c}}=-0.567\left(v_{\mathrm{c}}-v_{\mathrm{o}}\right)(\mathrm{GPa}) \text { for unsplitted phonons. }
$$

The above relations are useful in determining the total stresses (thermal and intrinsic stresses) developed in the sample. In order to calculate the thermal stress, the effect of differential thermal expansion between the coating and substrate with temperature must be taken into account to compare the calculated total stresses from the Raman spectra with purely thermal stress component using the following equation (6) given by Michler et al:

$$
\sigma_{\mathrm{th}}=\frac{E_{\mathrm{d}}}{1-\rho_{\mathrm{d}}} \int_{T_{\mathrm{o}}}^{T}\left[\alpha_{\mathrm{d}}(T)-\alpha_{\mathrm{s}}(T)\right] \mathrm{d} T,
$$

where $E$ and $\rho$ are Young's modulus and the Poisson ratio of the diamond, respectively, $\Delta \alpha$ the difference in the thermal expansion coefficients of the diamond $\left(\alpha_{\mathrm{d}}\right)$ coating and substrate $\left(\alpha_{\mathrm{s}}\right), T$ the deposition temperature and $T_{\mathrm{o}}$ the room temperature. The temperature dependence of linear thermal expansion coefficients for diamond $\left(\alpha_{\mathrm{d}}\right)$ and silicon $\left(\alpha_{\mathrm{s}}\right)$ can be expressed as a function of temperature $(T)$, as follows: ${ }^{19}$

For diamond, $\alpha_{\mathrm{d}}(T)=-5.91 \times 10^{-7}+6.64 \times 10^{-9}$

$$
T-1.663 \times 10^{-12} T^{2}
$$

For silicon, $\alpha_{\mathrm{s}}(T)=1.887 \times 10^{-6}+3.368 \times 10^{-9}$

$$
T-1.363 \times 10^{-12} T^{2} \text {. }
$$

The total stress $\left(\sigma_{\text {total }}\right)$ of a coating is the sum of the intrinsic stresses $\left(\sigma_{\text {intrinsic }}\right)$ induced during the growth and the thermal stresses $\left(\sigma_{\text {th }}\right)$. Total stresses are calculated from the peak shift of the Raman diamond line and thermal stresses are evaluated from equation (6). Thus intrinsic stresses are calculated from the following relationship: ${ }^{21}$

$$
\sigma_{\text {intrinsic }}=\sigma_{\text {total }}-\sigma_{\text {th }} .
$$

In the present work, the thermal stresses (compressive) are smaller than the intrinsic stresses, which are tensile in nature, thus making the overall stress tensile in nature. The evaluated stresses are dependent on the microstructure such as the grain size, the crystallographic orientation and the formation of disclinations due to the large local compressive stresses during grain coalescence and in particular, coherency strains at the coating-substrate interface for the small thickness of coating. ${ }^{19}$ Therefore, a semi-quantitative evaluation of the diamond quality was proposed by Ali et $a l^{22}$ by using the following relationship:

$$
Q=\frac{I_{\mathrm{d}}}{I_{\mathrm{glc}}+I_{\mathrm{d}}}(\%),
$$

where $Q$ is the 'quality factor' of the diamond coatings, $I_{\mathrm{d}}$ the intensity of the diamond peak and $I_{\mathrm{glc}}$ the intensity of the graphite-like carbon peak (or amorphous carbon). This factor gives an indication of the optimum experimental parameters. For pure diamond, the quality factor would be $100 \%$ since there is no graphite-like carbon.

\section{Experimental}

Diamond coatings were deposited on Si (100) substrate by microwave plasma CVD reactor (DiamoTek 1800, Lambda Technologies Inc., USA) at different process parameters as shown in table 1 . The microwave plasma was produced in the reaction chamber by excitation with $915 \mathrm{MHz}$ and 9$10 \mathrm{~kW}$ microwave power from a commercial magnetron (Richardson Electronics, Italy). The detailed description of the microwave plasma-assisted CVD reactor and growth process has been reported in our previous work. ${ }^{23}$ In order to increase the nucleation density of diamond crystals and obtain better uniformity over large area, the $p$-type (100) 
Table 1. Process parameters for deposition of MPCVD diamond coating.

\begin{tabular}{|c|c|c|c|c|c|c|c|c|c|}
\hline Sample id & $\begin{array}{l}\text { Time } \\
\text { (h) }\end{array}$ & $\begin{array}{c}\mathrm{H}_{2} \\
(\mathrm{sccm})\end{array}$ & $\begin{array}{c}\mathrm{CH}_{4} \\
(\mathrm{sccm})\end{array}$ & $\begin{array}{l}\text { Pressure } \\
\text { (Torr) }\end{array}$ & $\begin{array}{l}\text { Microwave } \\
\text { power }(\mathrm{kW})\end{array}$ & $\begin{array}{c}\text { Probe } \\
\text { position }(\mathrm{cm})\end{array}$ & $\begin{array}{c}\text { Short } \\
\text { position }(\mathrm{cm})\end{array}$ & $\begin{array}{c}\text { Stage } \\
\text { position }(\mathrm{cm})\end{array}$ & $\begin{array}{c}\text { Substrate } \\
\text { temperature }\left({ }^{\circ} \mathrm{C}\right)\end{array}$ \\
\hline W1 & 10 & 50 & 5 & 11 & 9.5 & 8.7 & 58.6 & 1 & $93-1110$ \\
\hline W2 & 10 & 1000 & 25 & 118 & 9 & 8.7 & 58.4 & 1 & 990-1062 \\
\hline W3 & 7 & 1000 & 10 & 110 & 9 & 8.7 & 58.5 & 0.2 & $943-1040$ \\
\hline
\end{tabular}

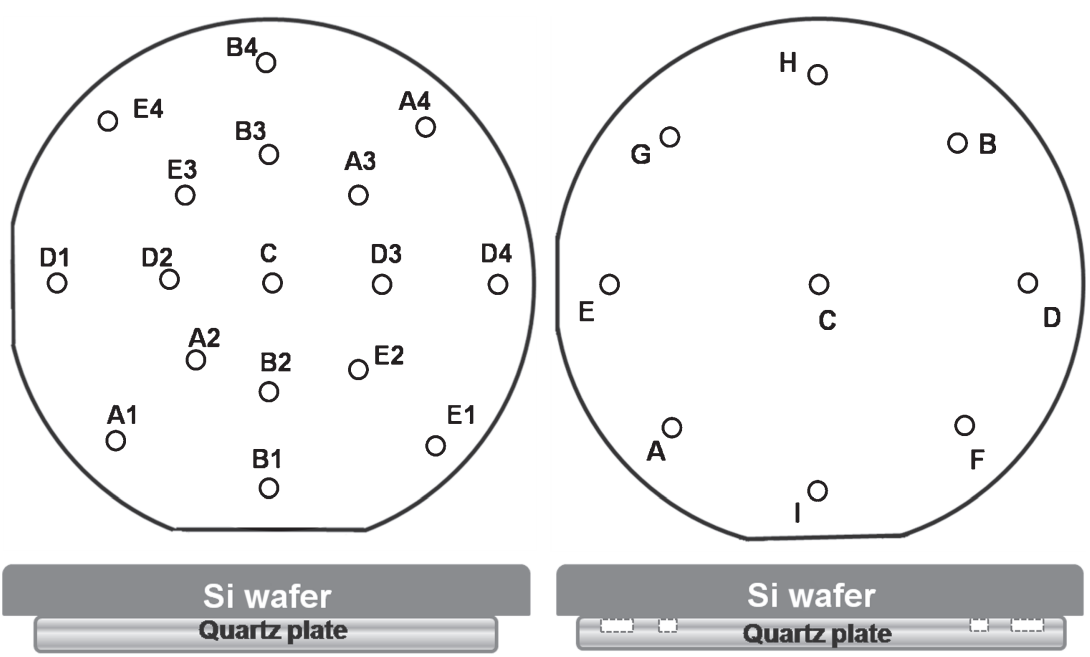

(a)

(b)

Figure 1. Schematics showing distribution of points for Raman spectroscopy measurement of MPCVD diamond coating on Si wafer along with cross-sectional features of Si-wafer and quartz plate of (a) W1 sample with flat quartz plate and (b) W2 and W3 samples with designed quartz plate.

silicon substrates of $100 \mathrm{~mm}$ diameter and $6 \mathrm{~mm}$ thickness were pretreated ultrasonically with detonation nanodiamond (DND) slurry. ${ }^{24}$ In order to minimize the impurity content in the diamond coating, ultra pure $(99.999 \%) \mathrm{CH}_{4}-\mathrm{H}_{2}$ gas mixtures were used as gaseous precursors during the deposition process.

The sample $\mathrm{W} 1$ was produced at microwave power of 9.5 $\mathrm{kW}$, chamber pressure of 118 Torr, $\mathrm{H}_{2}$ and $\mathrm{CH}_{4}$ flow rates of 500 and $5 \mathrm{sccm}$, respectively, with probe, short and stage positions as shown in table 1 . In this case the flat quartz plate was used underneath the $6 \mathrm{~mm}$ thick $\mathrm{Si}$ substrate to produce uniform thermal gradient in order to maintain homogeneous substrate temperature. However, there was some non-uniformity in substrate temperature from 934 to $1110^{\circ} \mathrm{C}$ among the 17 measured points as depicted in figure 1a and the maximum difference in substrate temperature was measured to be around $180^{\circ} \mathrm{C}$. In order to control the substrate temperature uniformity and suitable plasma geometry the geometry of the microwave cavity reactor parameters were modified and underneath quartz plate was designed in the manner as described in our previous work. ${ }^{23}$ After successful optimization, suitable values of the reactor parameters (table 1) like microwave power set at $9 \mathrm{~kW}$, chamber pressure at 118 and 110 Torr, $\mathrm{H}_{2}$ flow rate at $1000 \mathrm{sccm}, \mathrm{CH}_{4}$ flow rate at 25 and $10 \mathrm{sccm}$ were chosen to synthesize the diamond coating samples (W2 and W3, respectively). The temperature distribution on the silicon substrate was measured by a double-wavelength optical pyrometer (Williamson, USA, Model: PRO 82-40-C) by focusing it at different points of the substrate as shown in figure $1 \mathrm{a}$ and $\mathrm{b}$ with the same principle used in our earlier work. ${ }^{23}$

The Raman scattering measurements were performed at room temperature using a confocal micro-Raman spectrometer (LabRAM HR Vis. M/s. Horiba Jobin Yvon SAS, France) with all components fixed on a vibration damped optical table. At the laser excitation wavelength of $488 \mathrm{~nm}$, grating of $1800 / \mathrm{mm}, 100 \times$ objective having numerical aperture (NA) of 0.9 the best confocality resulted, i.e., the depth of focus was $\sim 2 \mu \mathrm{m}$. There was no loss of Raman signal with the confocal hole size of $100 \pm 5 \mu \mathrm{m}$. Under the above mentioned operating conditions of the spectrometer, the maximum diameter of the illuminated spot $(\sim 1.22 \times \lambda / \mathrm{NA})$ should be less than $1 \mu \mathrm{m}$ leading to no loss of Raman signal from the sample. ${ }^{25}$ The Raman spectrum was observed and recorded at different points of the large area diamond coatings repeatedly with an exposure time of $10 \mathrm{~s}$ each, extending over a range of frequencies with a non-zero line width. PL spectroscopy was carried out at the centre of each sample point by using the same experimental set-up used for microRaman spectroscopy. The $488 \mathrm{~nm}$ blue line $(2.543 \mathrm{eV})$ of the 
laser was used to excite luminescence; the spectra were taken within the range of $1.38-2.48 \mathrm{eV}(900-500 \mathrm{~nm}$ in a relative scale).

Transmission electron microscopy (TEM, Tecnai G $\mathrm{G}^{2}$ 30ST, $\mathrm{M} / \mathrm{s}$. FEI Company, USA) was carried out in order to obtain the direct evidence of microstructural defects within grains and grain boundary region of the diamond coating. The coating of about $3 \mathrm{~mm}$ size was chipped off from the substrate and was thinned down by argon ion milling with a $5 \mathrm{keV}$ argon ion beam and at $5^{\circ}$ incidence angle to obtain perforations for electron transparency.

The average surface roughness at different positions of the as-grown diamond coatings was measured by CSI (Contour GT-K, Bruker Nano GmbH, Germany) in non-contact mode. ${ }^{26}$ Each scan was performed using $10 \times$ objective lens on the surface area of $0.88 \times 0.66 \mathrm{~mm}$. The back scan and length parameter were set at 5 and $50 \mu \mathrm{m}$, respectively, for generating millions of data points. The thickness at different points of the as-grown diamond samples were measured by subtracting the thickness before diamond deposition and after diamond deposition on silicon wafer. To calculate the growth rates at different locations of the $100 \mathrm{~mm}$ diameter substrate area, the measured thickness value was divided by deposition time of the sample.

\section{Results and discussion}

\subsection{Characterization of coatings deposited before process optimization}

The Raman data were collected from seventeen different points arrayed along four different directions. Figure 2 shows the Raman spectra from diamond coating of sample W1 at the different points as shown in figure 1a. The Raman spectra show the characteristic diamond peaks as well as non-diamond graphitic hump present in some cases of the Raman spectrum. The inset figures show the corresponding diamond peak positions and peak shift with respect to theoretical diamond Raman line at $1332 \mathrm{~cm}^{-1}$.

The total stress was calculated from the peak shift of the characteristic Raman line using equation (1). Since the
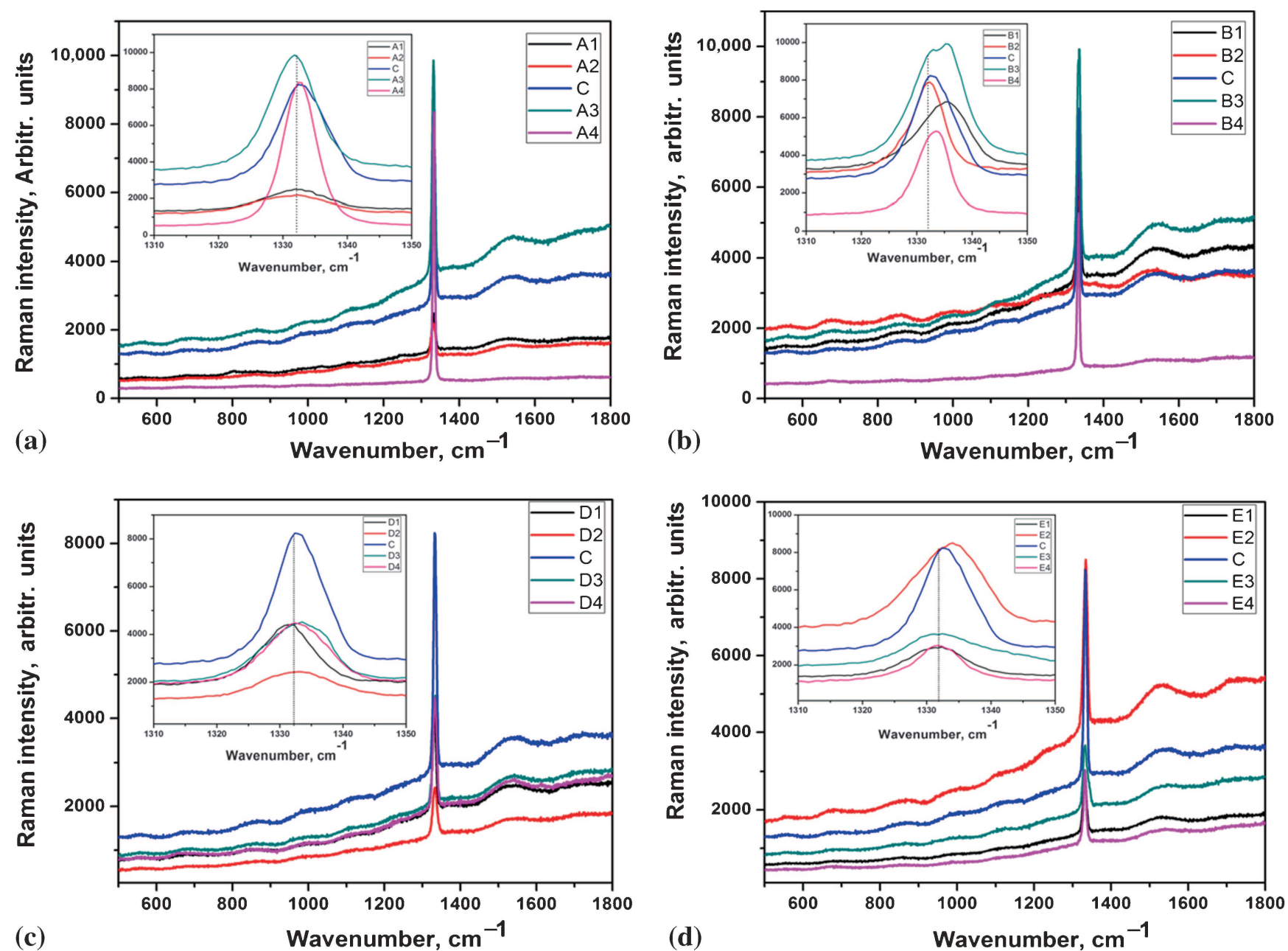

Figure 2. Raman spectrum of MPCVD diamond coating of sample W1 at points (a) A1, A2, C, A3, A4, (b) B1, B2, C, B3, B4, (c) D1, D2, C, D3, D4 and (d) E1, E2, C, E3, E4 in four different directions as shown in figure 1a. Inset figures show corresponding diamond peak positions and peak shift with respect to theoretical diamond Raman line at $1332 \mathrm{~cm}^{-1}$. 
split of the peaks is not clearly discernible for the points $\mathrm{A} 1, \mathrm{~A} 2$ and $\mathrm{C}$ in figure $2 \mathrm{a}$, point $\mathrm{B} 1$ in figure $2 \mathrm{~b}$, and for all points in figure $2 \mathrm{c}$ and $\mathrm{d}$, the average values of total stress at these points were calculated using equation (5). Sharp single Raman peaks with peak-shift were observed for points A3 and A4 in figure 2a, and points B2 and B4 in figure $2 \mathrm{~b}$. Hence, the uni-axial stresses present in those points were determined from the respective peak-shifts by using equation (2). Finally, for point B3 in figure $2 b$, the peak is split into two components due to the singlet and doublet phonon vibrations, and hence, equations (3) and (4) were used to evaluate the total stress From these microRaman studies, one may note that the Raman-shifts at different points occurred on either sides of the theoretical Raman line We therefore argue that the residual stresses present in the deposited diamond coating change in nature from pointto-point, ranging from compressive to tensile. The splitting of Raman peaks for diamond as observed in sample W1 at point B3 of figure 2b can be attributed to two possibilities. One possibility is the presence of non-hydrostatic biaxial stress or more complicated stress states in (111) planes leading to peak splitting according to the polarization selection rules. The second possibility could be the formation of nonuniform local stresses within the probed volume as proposed by other researchers. ${ }^{27}$

In order to evaluate the coating from point to point, the quality factor ( $Q$-factor) values in terms of percentage of $s p^{3}$ bonds were calculated from the Raman spectra obtained from different points with the help of equation (8). The temperature distribution over the substrate during deposition and variation of Q-factor at the seventeen different points of sample $\mathrm{W} 1$ are shown in figure 3 a. These $Q$-factor values were determined from the Raman spectra shown in figure 2 , by using equation (8). According to the literature, the quality ( $Q$-factor) of the diamond coating is expected to be better at higher substrate temperature. ${ }^{28}$ In figure $3 a$, at one of the substrate edge point labelled as A4 the substrate temperature was $1058^{\circ} \mathrm{C}$ and the quality factor of the coating was the highest, i.e., 93.46\% $s p^{3}$ diamond content, whereas, the opposite edge point (A1) having substrate temperature $960^{\circ} \mathrm{C}$ shows a $Q$-factor value of $58.43 \%$ while for the central point on substrate these values are $994^{\circ} \mathrm{C}$ and $70.11 \%$, respectively. There were also points $\mathrm{B} 4\left(1110^{\circ} \mathrm{C}\right)$ and $\mathrm{E} 4\left(1108^{\circ} \mathrm{C}\right)$ with higher temperatures. Therefore, there was a non-uniformity in substrate temperature from pointto-point during diamond growth. Such non-uniformity might have resulted due to the non-centric or, asymmetric plasma ball formation onto the substrate, i.e., slightly shifted plasma towards one edge. It was realized that as the substrate temperature increases from 934 to $1058^{\circ} \mathrm{C}$ the $Q$-factor of the coating improves from 61.58 to $93.46 \%$. However, for the highest substrate temperature at point $\mathrm{B} 4\left(1110^{\circ} \mathrm{C}\right)$, the $Q$-factor of the coating is $82.7 \%$. Thus it can be speculated that there is a certain critical temperature of about $1058^{\circ} \mathrm{C}$ for which coating of highest quality (93.46\%) is obtained and above which the coating quality decreases again with the increase in temperature. Butler et $a l^{29}$ showed a theoretical model to analyse the reactions for $\mathrm{H}$-atom abstraction, radical termination and chemisorptions of hydrocarbon species into the lattice during diamond growth and also discussed the substrate temperature dependence on this process for two different types of reactor, one is dc arc-jet and the other, the hot filament CVD reactor. They showed that the quality of the diamond film reaches a maximum at a certain substrate temperature $\left(\sim 1100^{\circ} \mathrm{C}\right)$ and falls off at higher temperatures due to competing desorption and decomposition reaction between $\mathrm{H}$-atom and methyl radicals.

The full-width at half-maximum (FWHM) of a Raman peak reflects the amount of disorder or defect density incorporated into the material. For each point on substrate, the FWHM values were measured from the characteristic diamond peaks and total stress was evaluated from the corresponding shifts of the diamond peak in the Raman spectrum. Figure $3 b$ shows the variation of FWHM and total stress present in the diamond coating at different points. It can be seen that the value of FWHM was the lowest at a point A4 $\left(5.88 \mathrm{~cm}^{-1}\right)$ and highest at point $\mathrm{A} 2\left(18.35 \mathrm{~cm}^{-1}\right)$, which is in agreement with the results discussed above as shown in figure 3a. Mallika and Komanduri ${ }^{21}$ also showed a similar variation of the FWHM of the diamond peak with the deposition temperatures. However, it can be seen that the FWHM of the diamond Raman line varied inversely with substrate temperature (figure 3a), i.e., higher the substrate temperature lower was the FWHM value. This means that defect density gets reduced at higher processing temperatures. This is most likely to be due to higher atom mobility at higher temperatures that help in annihilation of defects during diamond growth at higher temperatures.

It can be observed that the point $\mathrm{A} 2\left(960^{\circ} \mathrm{C}\right)$ has the highest FWHM value, i.e., highest defect density, but the total stress is relatively low $(+0.38 \mathrm{GPa})$ The increased FWHM suggests a greater defect density while the non-uniform strain results in reduced total strain within the analysed volume at A2. The value of the total stress is maximum at point B1 $\left(930^{\circ} \mathrm{C}\right)(-1.665 \mathrm{GPa})$ and minimum at point $\mathrm{E} 4\left(1110^{\circ} \mathrm{C}\right)$ $(0.035 \mathrm{GPa})$ with values of FWHM is 10.88 and $8.83 \mathrm{~cm}^{-1}$, respectively. This means that the same amount of defect density in the deposited coating may have either non-uniform or unidirectional stress. Although the value of the total stress $(-0.038 \mathrm{GPa})$ at point B2 is nearly equal to point E4, they are of different nature, i.e., the former is compressive and the latter tensile. So, there exists large inhomogeneity in stress distribution in the diamond coating all over the substrate.

Figure $3 \mathrm{c}$ shows the variation of intrinsic and thermal stress components at different points of the diamond coating of sample W1. The thermal and intrinsic stress components were calculated as a function of substrate temperature using equations (6) and (7), respectively. In most of the cases the nature of the intrinsic stress was tensile (' + ') in nature whereas the thermal stress was compressive ('-') in nature. ${ }^{30}$ The thermal stress values do not show much variation throughout the substrate except at two peripheral points B4 and E4 wherein the values are slightly low. It is interesting to note that in spite of the lowest value $(\sim+0.0053 \mathrm{GPa})$ 

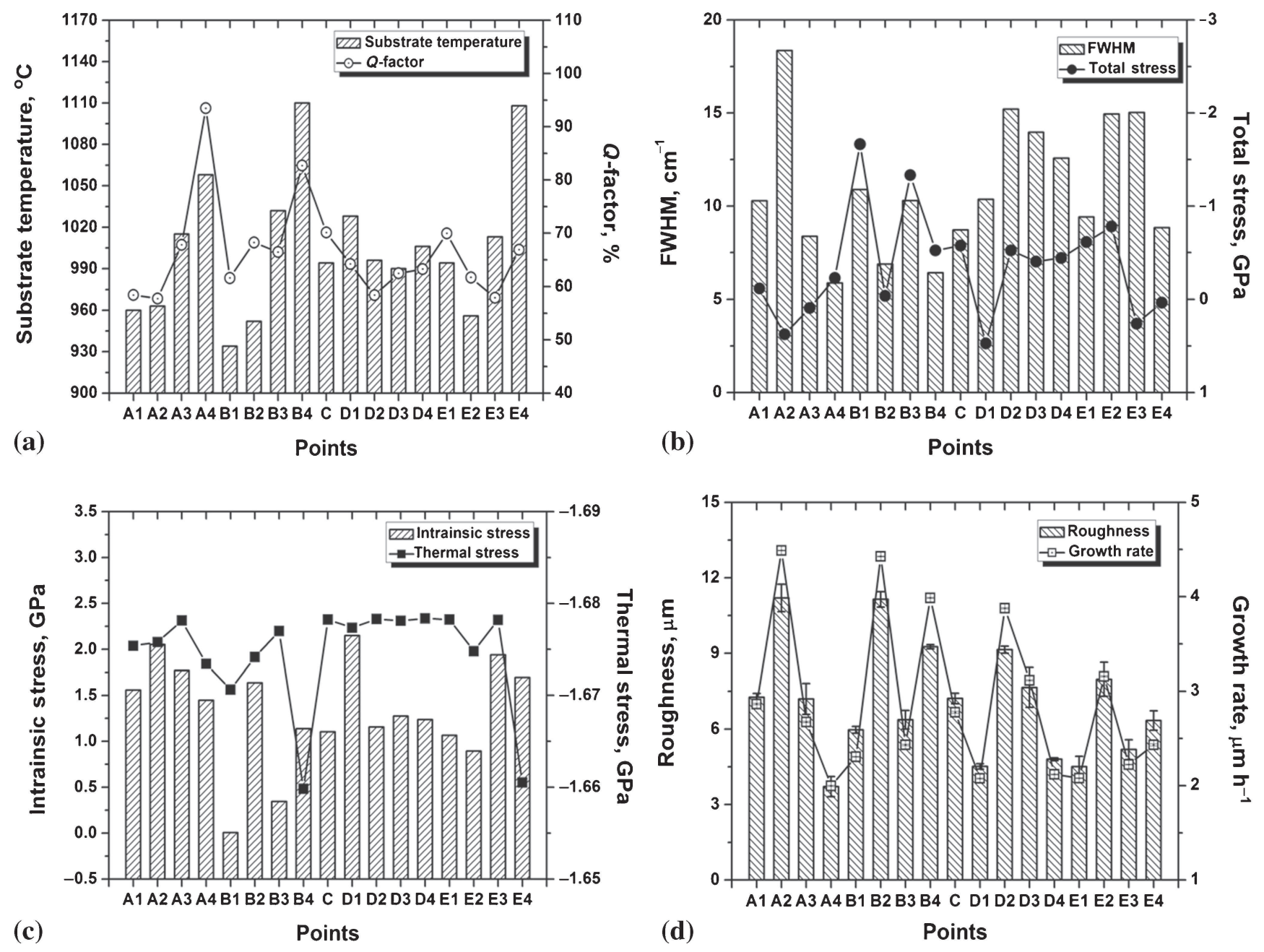

Figure 3. Graphical representation of the spatial distribution of (a) substrate temperature and $Q$-factor, (b) FWHM and total stress, (c) intrinsic stress and thermal stress and (d) average surface roughness and growth rate at 17 different points over the large area substrate as shown in figure 1a.

of intrinsic stress component at point B1 the total stress is maximum of all points due to a large thermal stress component $(\sim-1.670 \mathrm{GPa})$. This can be correlated with the lowest substrate temperature during growth at point B1. The relatively low values of thermal stress $(\sim-1.66 \mathrm{GPa})$ at points B4 and E4 may be correlated with high local temperatures $\left(\sim 1110^{\circ} \mathrm{C}\right)$ that might have helped in relieving thermal stresses during growth.

The variation of roughness and growth rate of the diamond coating at different points on sample W1 is shown in figure $3(\mathrm{~d})$. The values of roughness $(\sim 11 \mu \mathrm{m})$ and growth rate $\left(\sim 4.5 \mu \mathrm{m} \mathrm{h}^{-1}\right)$ are the highest at points $\mathrm{A} 2$ and $\mathrm{B} 2$, respectively. Whereas at other points, the roughness values vary from 3.2 to $9.3 \mu \mathrm{m}$ and growth rate varies from 2 to $4 \mu \mathrm{m}$ $\mathrm{h}^{-1}$. Thus, there are variations in average surface roughness as well as growth rate due to non-uniformity in substrate temperature distribution during deposition. As there was a substrate temperature variation by $180^{\circ} \mathrm{C}$ thermal stresses were generated throughout the substrate. It may also be noted that spectral humps corresponding to non-diamond phases are present in the Raman spectrum of large area diamond coating of sample W1. We recall that for sample W1, the $\mathrm{H}_{2}$ flow rate was $500 \mathrm{sccm}$ during deposition and $\mathrm{CH}_{4}$ flow rate was $1 \%$ of $\mathrm{H}_{2}$ flow. Therefore, the formation of non-diamond phases took place due to low hydrogen concentration in the microwave plasma. Thus, based on large area Raman spectroscopy analysis it was understood that there is a complexity of the substrate temperature distribution, which directly affects the quality and stress-picture of the MPCVD diamond coatings.

\subsection{Characterization of coating deposited after process optimization}

It may be understood from the results discussed above that in order to obtain good quality diamond coating with homogeneous stress distribution, uniform thickness and smoothness over large area, it is necessary to maintain good temperature uniformity throughout the substrate. For that purpose, optimization of process parameters such as microwave power, chamber pressure, methane concentration and reactor length as well as design of the quartz plate 
(as shown in figure 1b) underneath the Si substrate were necessary in order to obtain better temperature uniformity over the substrate. This has already been reported in our previous study. ${ }^{23}$ The influence of the substrate temperature and the methane concentration on the microscopic properties were systematically carried out by micro-Raman spectroscopy on MPCVD diamond coating samples grown using a $\mathrm{CH}_{4}-\mathrm{H}_{2}$ gas mixture.

Figure 4 shows the micro-Raman spectrum collected at nine different points on the as grown MPCVD diamond coatings, W2 (figure 4a) and W3 (figure 4b) on Si substrate at methane $\left(\mathrm{CH}_{4}\right)$ flow rates of (a) $2.5 \%$ and (b) $1 \%$, respectively, in $\mathrm{H}_{2}$ at a gas flow rate of $1000 \mathrm{sccm}$. In figure 4(a) all the Raman spectra consist of sharp diamond lines around $1332 \mathrm{~cm}^{-1}$ as well as non-diamond hump and luminescence band. The Raman spectra in figure $4 \mathrm{~b}$ on the other hand show very sharp diamond lines with trace amount of nondiamond content. These results suggest that a low $\mathrm{CH}_{4}$ concentration of $1 \%$ produces better quality diamond coating in terms of low defect density suggested by the smallest FWHM value $\left(3.265 \mathrm{~cm}^{-1}\right)$, i.e., sharp lines and smaller amount of non-diamond phase content

Figure $5 \mathrm{a}$ and $\mathrm{b}$ shows the variation of substrate temperature and corresponding $Q$-factor of those points of samples $\mathrm{W} 2$ and $\mathrm{W} 3$, respectively. For both figure $5 \mathrm{a}$ and $\mathrm{b}$, the substrate temperature difference was around $8^{\circ} \mathrm{C}$ between the maximum at centre and minimum at the peripheral points. Thus, better temperature uniformity was obtained over the substrate by the modified design of the quartz plate. Accordingly, the variation of $Q$-factor (quality) of the MPCVD diamond coating followed the substrate temperature results for both figure $5 \mathrm{a}$ and $\mathrm{b}$. On the other hand, figure $5 \mathrm{c}$ and $\mathrm{d}$ shows the variation of FWHM and total stress present for those points in the diamond coating of samples W2 and W3, respectively. Lower the FWHM value better is the quality of the coating and vice versa. The increase in the FWHM and non-diamond contents may be attributed to an increase in defect density and higher percentage of $\mathrm{CH}_{4}$ concentration, respectively. Broadening of Raman line could be due to two mechanisms. One is homogeneous (lifetime) broadening and the other being broadening due to the crystal size effect. In the case of homogeneous broadening, the FWHM of the diamond Raman peak is inversely proportional to the phonon lifetime. Since the phonon lifetime is shortened by scattering at defect sites and grain boundaries, the FWHM can be used as a convenient ranking indicator of the degree of 'crystal disorder'. In the case of broadening due to phonon confinement within a small domain due to small crystal size, the FWHM gets broader, the Raman peak shifts to lower wave numbers and the line shape becomes asymmetric towards lower wave numbers as the domain size decreases. ${ }^{31}$ Since in figure $4 \mathrm{~b}$, the diamond Raman peaks are highly symmetric, the phonon confinement effect was not considered and therefore small crystal size effect is ruled out Thus, the broadening of Raman peak and its shift towards larger wavenumber observed for W1 is suggestive of a possible presence of internal stress ${ }^{32}$ and crystallographic defects within the diamond grains.

The quality of W2 diamond coating varied from $72 \%$ to $52 \%$ from the centre to peripheral points of the sample as shown in figure 5a, whereas in case of sample W3 (figure 5b) diamond coating quality is significantly better and showed a $Q$-factor variation between 91.12 and $75 \%$ from central to the peripheral points. The improvement in quality distribution of the diamond coating of sample W3 is brought about by decreasing $\mathrm{CH}_{4}$ flow rate from $2.5 \%$ to $1 \%$ with respect to high $\mathrm{H}_{2}(1000 \mathrm{sccm})$. Figure $5 \mathrm{c}$ shows that for sample W2 the anisotropy in the total stress has significant variation $(-0.5$ to $-1.15 \mathrm{GPa})$ from point-to-point over the large area coating. However, for sample W3 it can be observed from figure $5 \mathrm{~d}$ that the total stress values show less variation with respect to the central point $\mathrm{C}$ having the lowest stress value $(-0.33 \mathrm{GPa})$ and the two peripheral points $\mathrm{A}(-0.90 \mathrm{GPa})$ and $\mathrm{G}(-0.80 \mathrm{GPa})$ show relatively high stress values of the diamond coating of sample W3. These results suggest that for low $\mathrm{CH}_{4}$ concentration of $1 \%$, improvements in quality of diamond coating as well as stress uniformity in the coating are obtained and a high
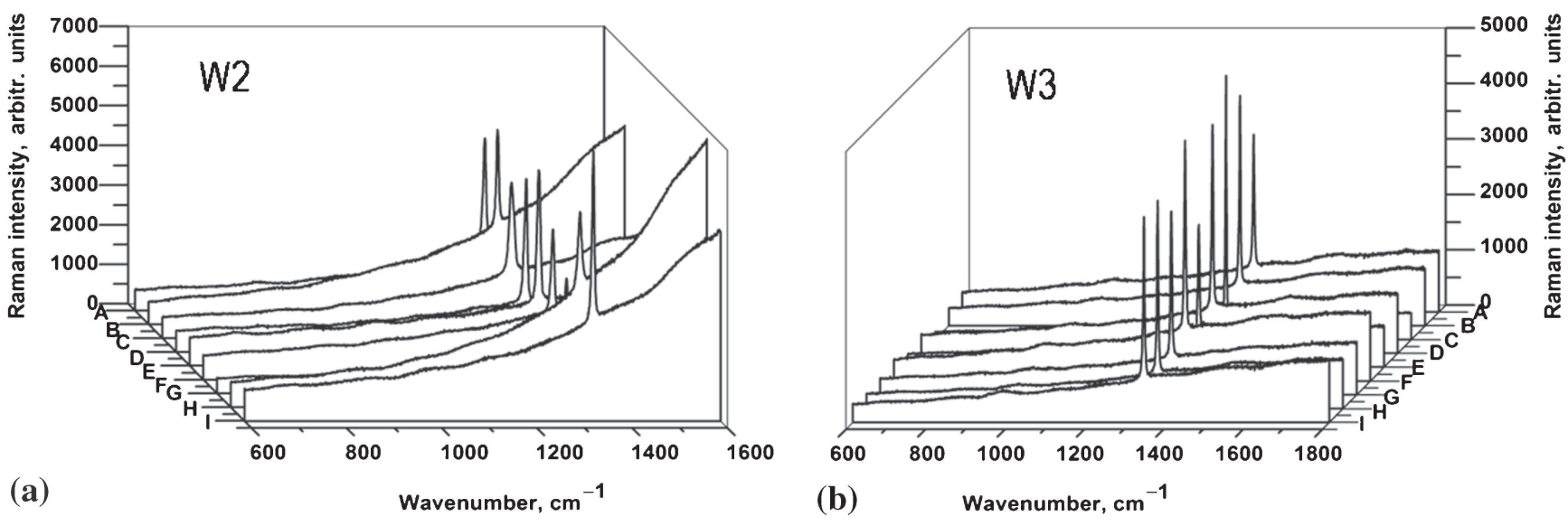

Figure 4. Raman spectrum of MPCVD diamond coating of samples (a) W2 and (b) W3 at nine different points A, B, C, D, E, F, G, H, I in four different directions as shown in figure $1 \mathrm{~b}$. 

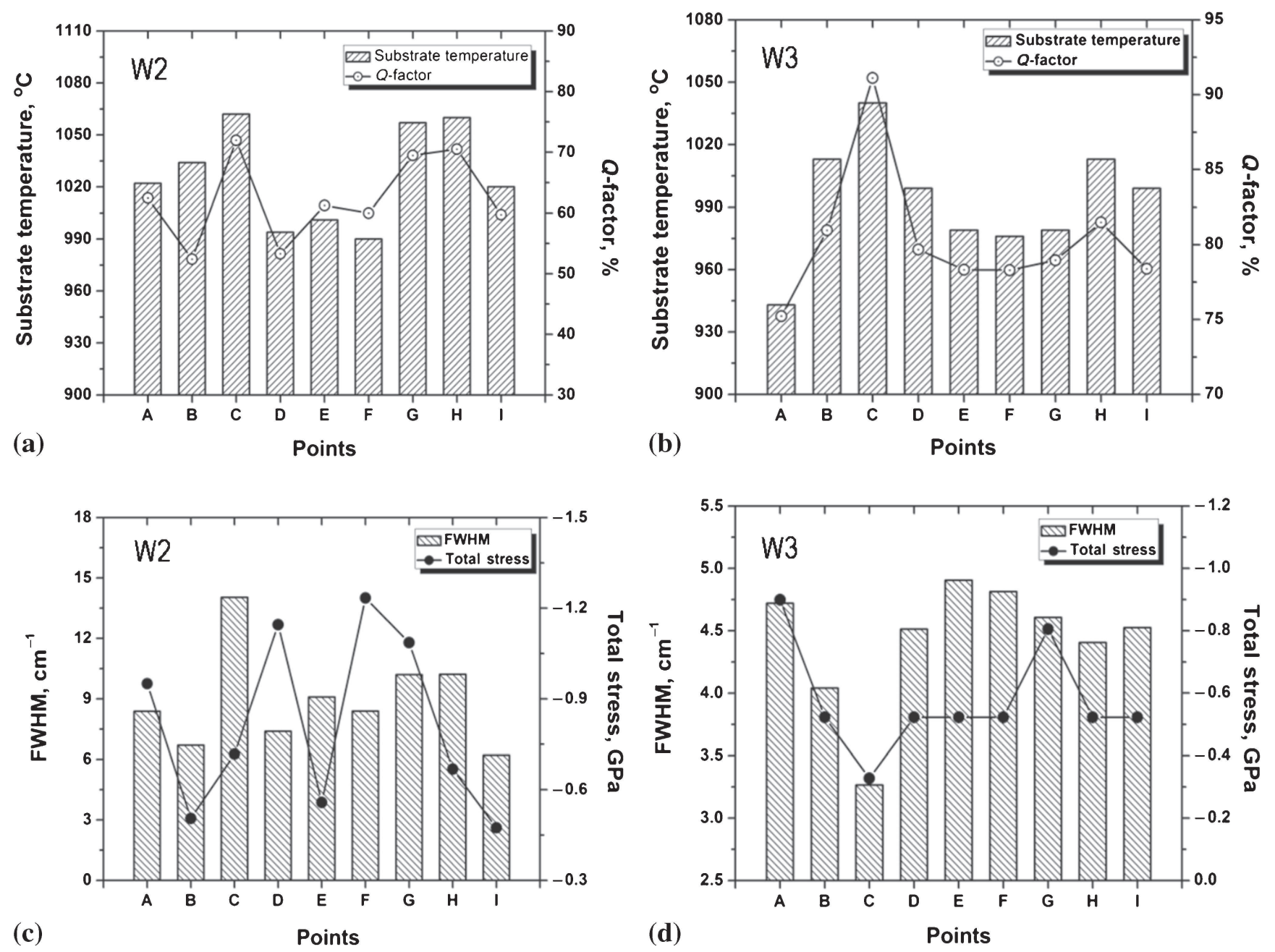

Figure 5. Graphical representation of the special distribution of substrate temperature and $Q$-factor for samples (a) W2 and (b) W3, FWHM and total stress for samples (c) W2 and (d) W3 at nine different points over the large area substrate as shown in figure 1b.

substrate temperature of about $1030^{\circ} \mathrm{C}$ with low methane concentration helps produce better diamond coating.

Figure 6a shows the non-uniform distribution of intrinsic as well as thermal stresses present in sample W2. Both the stress distributions are quite uniform in case of sample W3 as can be seen from figure $6 \mathrm{~b}$. Variation of roughness and growth rate was shown in figure $6 \mathrm{c}$ and $\mathrm{d}$ for diamond coatings of samples W2 and W3, respectively. From figure $6 \mathrm{c}$ it can be noted that the roughness had almost the same value $(\sim 0.7 \mu \mathrm{m})$ at the peripheral points but roughness at the centre point ' $\mathrm{C}$ ' was higher $(1.15 \mu \mathrm{m})$ than those at the peripheral region. This figure also shows that the growth rate was the highest, i.e., $9.2 \mu \mathrm{m} \mathrm{h}^{-1}$ at the centre and varied within (5.5-7.5) $\mu \mathrm{m} \mathrm{h}^{-1}$ at different peripheral points of the coating of sample W2. Whereas, similar variation of roughness and growth rate was observed in figure $6 \mathrm{~d}$ for W3 sample and both the values were minimum at the centre and higher at the peripheral regions. The value of roughness at the centre ( $\mathrm{C}$ point) was $0.43 \mu \mathrm{m}$ and the peripheral points vary in roughness from 0.72 to $1.08 \mu \mathrm{m}$. Also the growth rate had the lowest value $\left(\sim 2 \mu \mathrm{m} \mathrm{h}^{-1}\right)$ at centre and varied from 2.8 to
$4.7 \mu \mathrm{m} \mathrm{h}^{-1}$ at different peripheral points of the sample W3. So, the thickness uniformity and smoothness of the diamond coating of samples W2 and W3 were better than sample W1 due to more uniform substrate temperature. In terms of quality and stress uniformity W3 sample was much better than W2 due to low methane concentration (1\%) relative to high hydrogen content.

Figure 7 shows the micro-PL spectra at the centre (point $\mathrm{C}$ in figure 1a and $\mathrm{b}$ ) of the MPCVD diamond coatings of samples (a) W1, (b) W2 and (c) W3 under excitation by blue laser of wavelength of $488 \mathrm{~nm}$ and energy of $2.543 \mathrm{eV}$. All these spectra are composed of a sharp narrow PL emission peak at $\sim 2.38 \mathrm{eV}(\sim 521 \mathrm{~nm})$, a strong PL emission peak at $\sim 1.68 \mathrm{eV}(\sim 739 \mathrm{~nm})$ and a broad PL band, which appears in between these two peaks. The PL feature at $1.68 \mathrm{eV}$ is known to be commonly associated with the silicon-vacancy centre $[\mathrm{Si}-\mathrm{v}]^{0}$, present near the interface between diamond coating and the Si substrate. The proposed mechanism for the formation of $[\mathrm{Si}-\mathrm{v}]^{\circ}$ centre is based on the etching of the silicon substrate by highly reactive plasma during the early stages of the growth process wherein $\mathrm{Si}$ atoms are released by the 

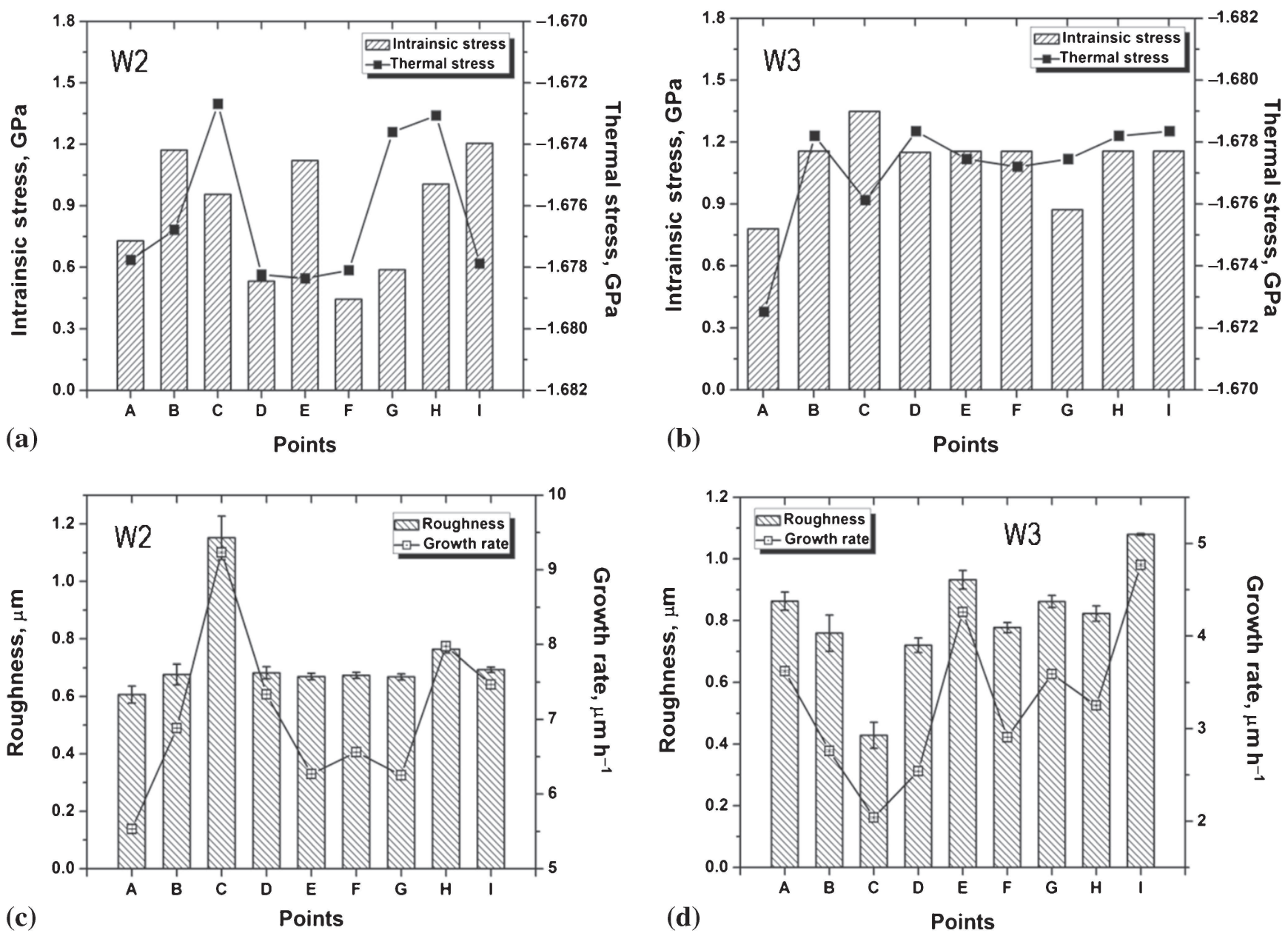

Figure 6. Graphical representation of the special distribution of intrinsic stress and thermal stress for samples (a) W2 and (b) W3, average surface roughness and growth rate for samples (c) W2 and (d) W3 at nine different points over the large area substrate as shown in figure $1 b$.

substrate and incorporated into the diamond matrix. ${ }^{6,7,13}$ The characteristics of these spectra show the dependence of deposition parameters like microwave power, pressure and $\mathrm{CH}_{4}-$ $\mathrm{H}_{2}$ flow rate. With the increase of $\mathrm{CH}_{4}$ flow rate from $1 \%$ to $2.5 \%$ with respect to $\mathrm{H}_{2}$ the $[\mathrm{Si}-\mathrm{v}]^{\circ}$ peak intensity increases (as for W2) and the maxima of the PL emission band is blue shifted to $\sim 2.2 \mathrm{eV}$. These bands of the PL emissions spectra may have its origin in the transition of excited photocarriers from $[\mathrm{Si}-\mathrm{V}]^{\circ}$ centres into the band gap introduced by disordered graphite-like phases in the coating structure. ${ }^{33}$

It can also be seen from figure 7 that within the PL band tiny peaks are present around 1.941 and $2.191 \mathrm{eV}$ for the samples W1, W2 and less prominently for W3. These peaks are associated with zero phonon lines (ZPLs) and conventionally denoted by $[\mathrm{N}-\mathrm{v}]^{-}$and $[\mathrm{N}-\mathrm{v}]^{\circ}$ which are related to single substitution of nitrogen associated with a vacancy in the negative $(\mathrm{N}-\mathrm{v})^{-}$charge and neutral $(\mathrm{N}-\mathrm{v})^{\mathrm{o}}$ statesrespectively. ${ }^{32}$ Thus, it turns out that for $\mathrm{W} 3$, the concentration of $[\mathrm{N}-\mathrm{v}]^{-}$and $[\mathrm{N}-\mathrm{v}]^{\circ}$ defects in diamond crystals are significantly low so that the emission from the $\mathrm{N}-\mathrm{v}$ centres becomes very weak with respect to other peaks. Therefore, this PL result is in agreement with our Raman spectroscopy results that as the $\mathrm{CH}_{4}: \mathrm{H}_{2}$ concentration ratio is decreased and total gas flow rate is increased the crystal quality of diamond grains is improved through lowering of defect concentration

The energy bands take maxima around $2.03 \mathrm{eV}$ for $\mathrm{W} 1$ and $\mathrm{W} 3$ whereas it is $2.2 \mathrm{eV}$ for W2 in the PL spectra, as can be seen in figure 7a, c and b, respectively. Similar observation was made by other researcher. ${ }^{32}$ The band at around $2.03 \mathrm{eV}$ is due to the vibronic band, which is related to the presence of line and point defects in the diamond crystals. It is also found that the vibronic band in the PL spectra of figure $7 \mathrm{a}$ and $\mathrm{b}$ consists of additional low intensity peaks. It is important to note that the intensity of the PL band maxima as well as low intensity peaks in figure $7 \mathrm{a}$ and $\mathrm{b}$ are much more in comparison with figure 7c. This may be due to the different deposition conditions particularly low hydrogen content (W1) and high methane concentration (W2) which may create more embedding $s p^{2}$ graphitic sites within the $s p^{3}$ diamond matrix and generate defect states in the $\pi$ and 


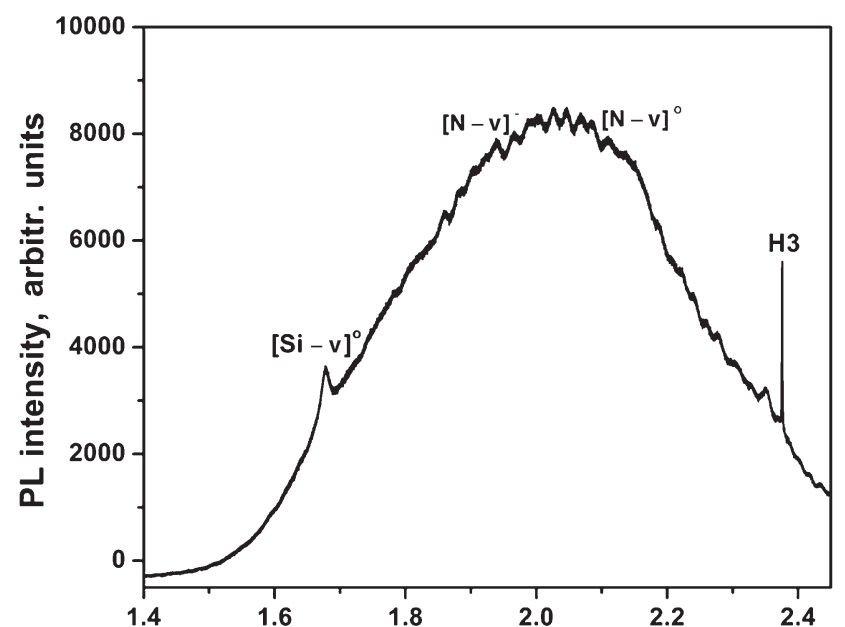

(a)
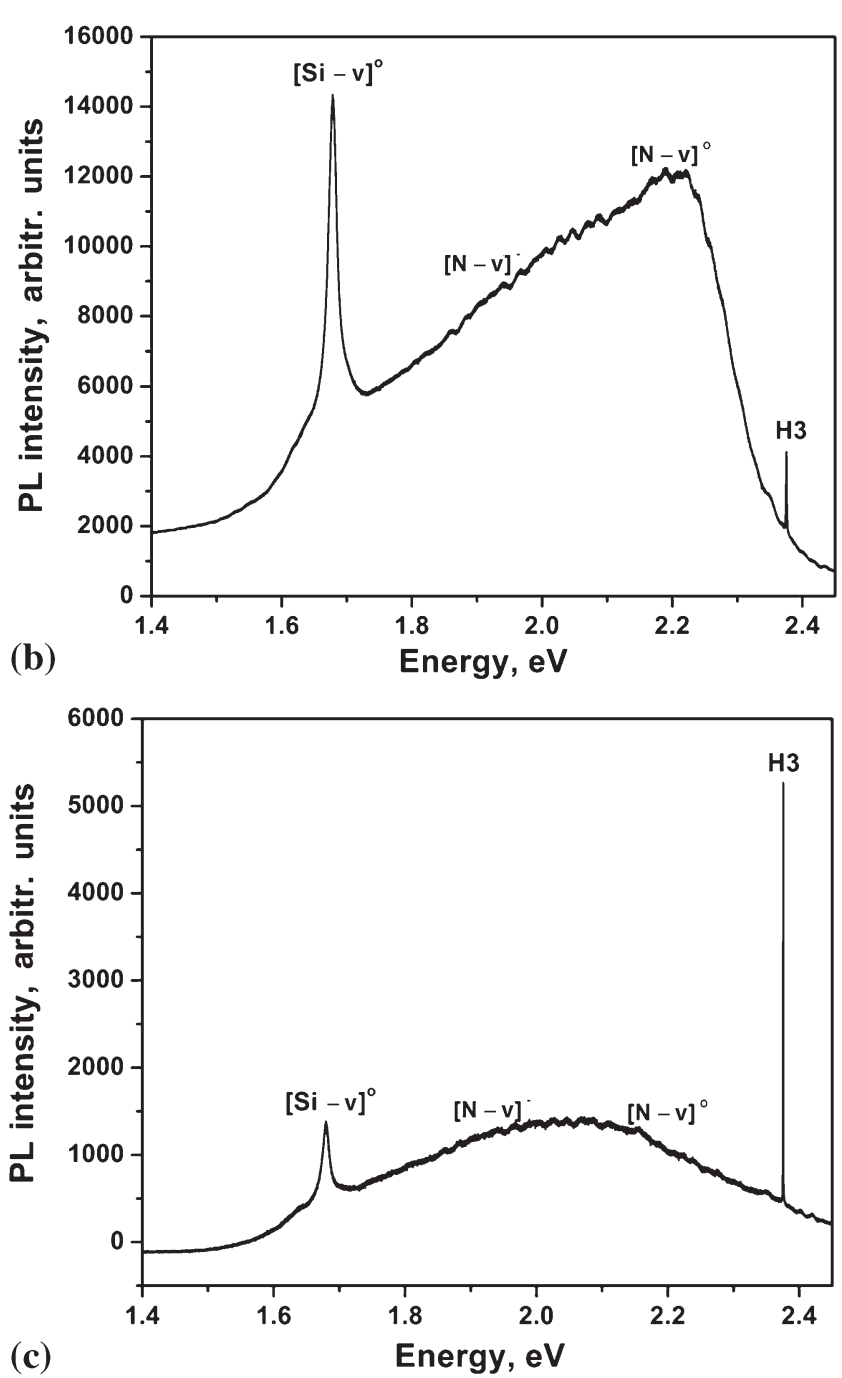

Figure 7. The typical micro-photoluminescence spectra at the centre of the MPCVD diamond coatings of samples (a) W1, (b) W2 and (c) W3.

$\pi^{*}$ electronic bands. ${ }^{34}$ Therefore, the observed low intensity peaks within the broad PL band are related to the electronic transitions between these different defect levels. As
PL is a radiative process involving absorption of a photon, followed by its subsequent emission from the surface of the coating the relative intensity and the position of the PL band maxima may vary from sample to sample. The sharp peak at $2.38 \mathrm{eV}$ seen in the PL spectrum shown in figure 7 suggests the trapping of vacancies within the cubic growth zone to form nitrogen-vacancy-nitrogen complex or, the $\mathrm{H} 3$ defect. ${ }^{10}$ That means that two nitrogen atoms have a trigonal symmetry with the carbon atoms. Such complex can form along $\langle 110\rangle$ vectors lying within the $\{100\}$ growth planes in each cubic growth zone. So the variation of intensity of the $\mathrm{H} 3$ peak depends on the different process parameters for different samples. It has been observed that the $\mathrm{H} 3$ intensity is the highest for sample W3 as depicted in figure 7c of the PL spectra. Since it was deposited at low methane concentration (1\%) with respect to high hydrogen content $(1000 \mathrm{sccm})$ and low chamber pressure (110 Torr), formation of such complex within the crystalline diamond was favoured during the early stages of growth. But its formation was significantly reduced for sample W2 in figure $7 \mathrm{~b}$ due to the increase of methane concentration to $2.5 \%$ with same $\mathrm{H}_{2}$ content and with chamber pressure increased to 118 Torr. Further increment of intensity was observed in figure 7 a for sample $\mathrm{W} 1$ due to the low gas content, i.e., $1 \% \mathrm{CH}_{4}$ with respect to $500 \mathrm{sccm}$ of $\mathrm{H}_{2}$. Although there had been extensive research work done in this area no definite conclusion about the nature of the $\mathrm{H} 3$ optical centre has yet been drawn. Therefore, it is being suggested that the presence of less amount of $\mathrm{CH}_{4}$ molecule in the plasma at a relatively low pressure will enhance the formation of such complex which get reduced at relatively higher pressure and higher methane concentration.

Figure $8 \mathrm{a}$ and $\mathrm{b}$ shows the typical bright-field TEM images of the diamond coating samples W1 and W3, respectively. The TEM results provide the direct evidence of the presence of defects mostly dislocations, microtwins, stacking faults, within the diamond grains and even amorphous regions in the grain-boundaries. These results also illustrate the effect of the reactant gas $\left(\mathrm{CH}_{4}-\mathrm{H}_{2}\right)$ flow rate with these defects. For high flow rates of $\mathrm{CH}_{4}-\mathrm{H}_{2}$, the defect density in $\mathrm{W} 3$ grains, as seen in figure $8 \mathrm{~b}$ is less than that for the diamond grains of W1 shown in figure 8a. These results are in good agreement with the Raman and PL studies. This might be due to the fast gas exchange that occurs in the presence of high methane and hydrogen concentration in the reaction chamber. ${ }^{35}$ The varied density of defects from sample W1 to W3 suggests that different experimental growth conditions promote different crystallographic defects. In case of W3, the diamond grains grew with crystallographic orientations that favour nucleation of stacking faults and twins to relax the stress, while in W1 the growth of diamond grains took place under stress generating defects like dislocations. ${ }^{36}$

Figure 9 shows the typical CSI images at the centre of the MPCVD diamond coatings of samples (a) W1, (b) W2 and (c) W3 with surface area of $0.88 \times 0.66 \mathrm{~mm}$ in order to assess the three-dimentional surface roughness of as-grown surfaces at nanometer resolution in terms of average surface roughness $\left(R_{\mathrm{a}}\right)$. The CSI images were taken from where the 


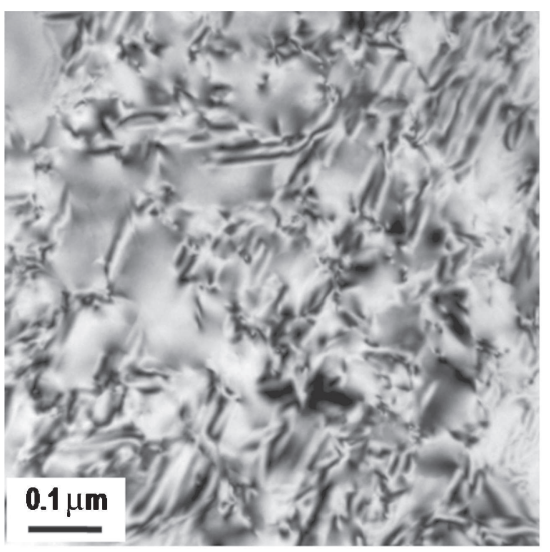

(a)

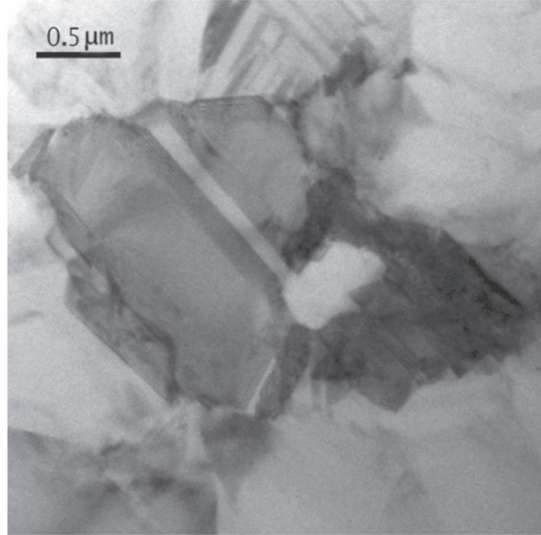

(b)

Figure 8. Representative bright-field TEM images showing grain morphology in the diamond coatings (a) W1 and (b) W3.

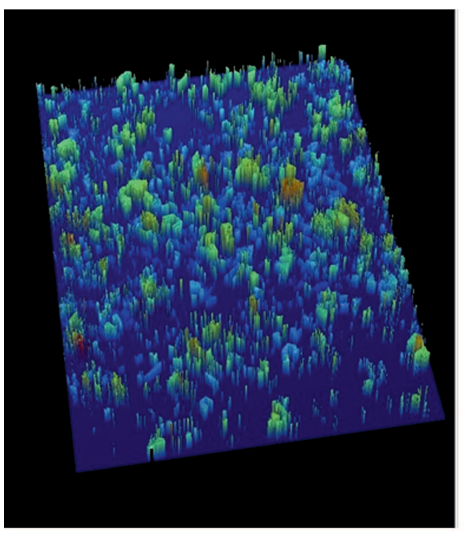

(a)

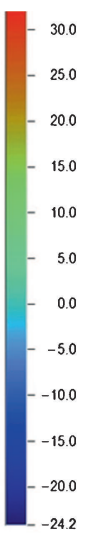

(b)

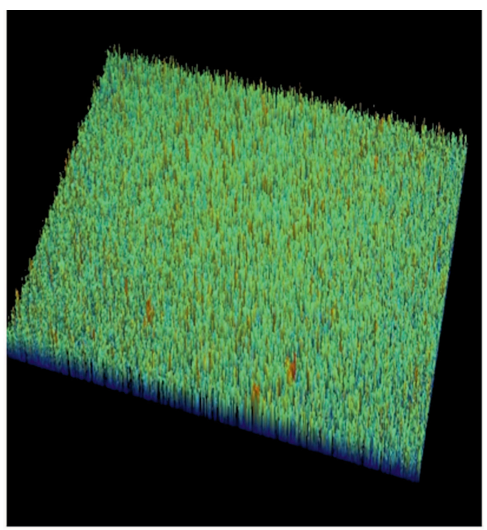

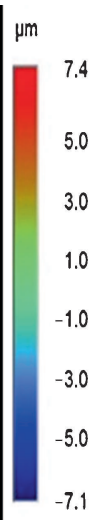

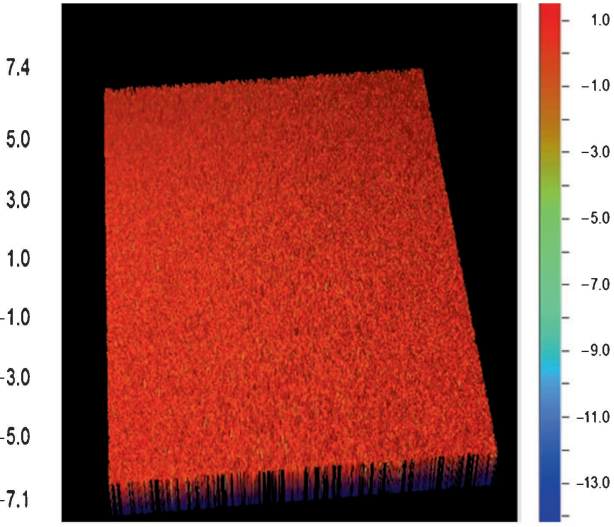

(c)

Figure 9. Typical coherence scanning interferometry (CSI) images for three-dimensional surface topography to determine the average surface roughness at the centre of the MPCVD diamond coatings of samples (a) W1, (b) W2 and (c) W3.

PL spectra were observed. In case of sample W1 higher surface roughness values were obtained due to the presence of bigger diamond octahedral pyramids with inhomogeneous peaks and valleys as shown in figure 9a. In case of samples W2 and W3 the average value of surface roughness decreased and better thickness uniformity was obtained by decreasing methane flow rate as shown in figure $9 \mathrm{~b}$ and $c$, respectively.

\section{Conclusions}

The following conclusions can be drawn from the above discussions:

(i) The detailed micro-Raman spectroscopy study signifies that the higher amount of non-diamond phases are present in the deposited coating (W1) before process optimization condition and it was significantly reduced in the deposited coating (W3) after optimization. (ii) The non-uniformity in stress distribution ranging from tensile to compressive from point to point over the large area coating grown under non-optimized condition resulted from non-uniform substrate temperature.

(iii) Improvements in MPCVD diamond coating quality and stress uniformity were achieved through optimization of the growth parameters under low methane concentration and a modified design of quartz plate for better temperature uniformity over the substrate.

(iv) Photo-luminescent spectroscopy study showed that the defect centres and impurities in the diamon coatings originate due to incorporation of $\mathrm{Si}$ atoms from the substrate.

(v) The crystal defects in the diamond grains and the presence of graphitic phase are the major source of compressive intrinsic stress which was clearly indentified from the PL spectra as well as transmission electron microscopy images. 


\section{Acknowledgements}

We gratefully thank Council for Scientific and Industrial Research (CSIR), India, for financial support from a networked project. The authors would also like to gratefully thank the Directors, CSIR - Central Glass and Ceramic Research Institute (CSIR-CGCRI)-Kolkata, India and CSIR - Central Electronics Engineering Research Institute (CSIR-CEERI)-Pilani, India, for continuous encouragement in carrying out the present work and granting permission to publish. We would also like to thankfully dedicate the present work to the memories of past project leader late Dr. D. Basu for initiating and establishing the present research activity.

\section{References}

1. Schwander M and Partes K 2011 Diam. Relat. Mater. 201287

2. May P W 2000 Philos. Trans. R. Soc. Lond. A 358473

3. Zuo S S, Yaran M K, Grotjohn T A, Reinhard D K and Asmussen J 2008 Diam. Relat. Mater. 17300

4. Railkar T A, Kang W P, Windischmann H, Malshe A P, Naseem H A, Davidson J L and Brown W D 2000 CRC Crit. Rev. Sol. State 25163

5. Pickard C D O, Davis T J, Wang W N and Steeds J W 1998 Diam. Relat. Mater. 7238

6. Donato M G, Faggio G, Marinelli M, Messina G, Milani E, Paoletti A, Santangelo S, Tucciarone A and Rinati G V 2001 Diam. Relat. Mater. 101535

7. Donato M G, Faggio G, Marinelli M, Messina G, Milani E, Paoletti A, Santangelo S, Tucciarone A and Rinati G V 2001 Eur. Phys. J. B 20133

8. Prawer S and Nemanich R J 2004 Philos. Trans. R. Soc. Lond. A 3622537

9. Ferrari A C 2002 Diam. Relat. Mater. 111053

10. Fish M L, Massler O, Reid J A, Gregor R M and Comins J D 1999 Diam. Relat. Mater. 81511

11. Erasmus R M, Comins J D, Mofokeng V and Martin Z 2011 Diam. Relat. Mater. 20907

12. Erasmus R M, Daniel R D and Comins J D 2011 J. Appl. Phys. 109013527

13. Donato M G, Faggio G, Messina G, Santangelo S, Marinelli M, Milani E, Pucella G and Rinati GV 2004 Diam. Relat. Mater. 13923
14. Diniza A V, Ferreirac N G, Corata E J and Trava-Airoldi V J 2004 Diam. Relat. Mater. 13526

15. Leeds S M, Davis T J, May P W, Pickard C D O and Ashfold M N 1998 Diam. Relat. Mater. 7233

16. May P W, Smith J A and Rosser K N 2008 Diam. Relat. Mater. 17199

17. Fana Q H, Gracio J and Pereira E 2000 Diam. Relat. Mater. 9 1739

18. Kuo C T, Wu J Y, Lin C H, Lub T R and Sung C M 2001 Mater. Chem. Phys. 72114

19. Michler J, Mermoux M, Kaenel Y V, Haouni A, Lucazeau G and Blan E 1999 Thin Solid Films 357189

20. Nibennanoune Z, George D, Antoni F, Ahzi S, Ruch D, Gracio J and Remond Y 2012 Diam. Relat. Mater. 22105

21. Mallika K and Komanduri R 2001 Thin Solid Films 396145

22. Ali N, Neto V F, Mei S, Cabral G, Kousar Y, Titus E, Ogwu A A, Misra D S and Gracio J 2004 Thin Solid Films 469 154

23. Mallik A K, Pal K S, Dandapat N, Guha B K, Datta S and Basu D 2012 Diam. Relat. Mater. 3053

24. Shenderova O, Hens S and McGuire G 2010 Diam. Relat. Mater. 19260

25. Datta J, Ray N R, Sen P, Biswas H S and Vogler E A 2012 Mater. Lett. 71131

26. Petzing $\mathrm{J}$ and Leach R 2010 Measurement good practice guide No. 116

27. Kaenel Y V, Stiegler J, Michler J and Blank E 1997 J. Appl. Phys. 814

28. Das D, Jayaseelan V, Ramamurti R, Kukreja R S, Guo L and Singh R N 2006 Diam. Relat. Mater. 151336

29. Butler J E, Woodin R L, Brown L M and Fallon P 1993 Philos. Trans. R Soc. 342209

30. Wanlu W, Kejun L, Jinying G and Aimin L 1992 Thin Solid Films 215174

31. Bergman L and Nemanich R J 1995 J. Appl. Phys. 786709

32. Iakoubovskii K and Adriaenssens G J 2000 Diam. Relat. Mater. 91349

33. Rahman S A, Othman M Z and May P W 2012 Adv. Mater. Res. $\mathbf{5 0 1} 271$

34. Pandey M and Patil D S 2007 Diam. Relat. Mater. 161912

35. Nistor L, Landuyt J V and Ralchenko V 1999 Phys. Stat. Sol. (A) 1745

36. Comins J D, Daniel R D, Erasmus R M and Brookes E J 2000 Diam. Relat. Mater. 91115 